\title{
Bone Metastatic LNCaP-Derivative C4-2B Prostate Cancer Cell Line Mineralizes In Vitro
}

\author{
Din-Lii Lin, ${ }^{1}$ Catherine P. Tarnowski, ${ }^{4}$ Jian Zhang, ${ }^{2}$ Jinlu Dai, ${ }^{1}$ Emileigh Rohn, ${ }^{1}$ \\ Avni H. Patel, ${ }^{1}$ Michael D. Morris, ${ }^{4}$ and Evan T. Keller ${ }^{1,2,3 *}$ \\ 'Unit for Laboratory Animal Medicine, University of Michigan, Ann Arbor, Michigan \\ ${ }^{2}$ Department of Pathology, School of Medicine, University of Michigan, Ann Arbor, Michigan \\ ${ }^{3}$ Institute of Gerontology, University of Michigan, Ann Arbor, Michigan \\ ${ }^{4}$ Department of Chemistry, University of Michigan, Ann Arbor, Michigan
}

\begin{abstract}
BACKGROUND. Prostate cancer frequently metastasizes to bone. However, unlike many other tumors that produce osteolytic lesions, prostate cancer produces osteoblastic lesions through unknown mechanisms. In the current study, we explored the ability and mechanism of an osteotropic prostate cancer cell line (C4-2B) to induce mineralization.

METHODS. C4-2B cells were grown in promineralization media. Mineral deposition was characterized using von Kossa staining, calcium retention, alizarin red staining, Raman spectroscopy, and electron microscopy. Expression of osteoblast-related proteins was determined by RT-PCR. The nuclear level of the bone-specific transcription factor Cbfa1 was determined using western analysis and the effect of inhibiting Cbfa1 function, using a "decoy" Cbfa1 response element oligo, on mineralization was determined.

RESULTS. The studies demonstrated that C4-2B cells, but not its nonosteotropic parent cell line $\mathrm{LNCaP}$, has an osteoblastlike phenotype including production of alkaline phosphatase, osteocalcin, osteonectin, bone sialoprotein, osteoprotegerin (OPG), and OPG ligand. Most importantly, the $\mathrm{C} 4-2 \mathrm{~B}$ cells produced hydroxyapatite mineral in vitro. Furthermore, $\mathrm{C} 4-2 \mathrm{~B}$ cells expressed high nuclear levels of the bone-specific transcription factor $\mathrm{Cbfa1}$, compared to LNCaP cells, which accounts for their ability to produce bone-specific proteins. Inhibition of $\mathrm{Cbfa} 1$, using decoy DNA Cbfa1 response elements, abrogated the ability of $\mathrm{C} 4-2 \mathrm{~B}$ to produce mineral. Finally, we determined that $C 4-2 B$ cells express bone morphogenic protein-7, a known inducer of $\mathrm{Cbfa} 1$ expression.

CONCLUSIONS. These data demonstrate a novel mechanism through which prostate cancer cells may directly contribute to the osteoblastic component that characterize their skeletal metastatic lesions. Prostate 47:212-221, 2001. @ 2001 Wiley-Liss, Inc.
\end{abstract}

KEY WORDS: prostate cancer; bone metastasis; osteoblast; osteoprotegerin; Cbfa1; BMP-7

\section{INTRODUCTION}

Prostate carcinoma frequently metastasizes to bone [1] resulting in both osteoblastic and osteolytic lesions [2]. The mechanism through which prostate carcinoma induces osteoblastic lesions are currently not defined. To understand the mechanism of skeletal metastasis, several animal models of skeletal metastasis or intraosseous tumor growth using human prostate cancer cell lines injected subcutaneously (s.c.), orthotopically
Abbreviations: OPG, osteoprotegerin; BSP, bone sialoprotein; OCN, osteocalcin; OSN, osteonectin; RANKL, receptor activator of NFkappaB ligand; Cbfa1, core binding factor-alpha; BMP-7, bone morphogenic protein.

Grant sponsor: USAMRMC; Grant number: DAMD 17-00-1-053; Grant sponsor: National Institutes of Health; Grant numbers: P50 CA69568 and R01 AG15904.

*Correspondence to: Dr. Evan T. Keller, University of Michigan, Department of Pathology, Unit for Laboratory Animal Medicine, 5305 CCGC, 1500 East Medical Center Drive, Ann Arbor, MI 481090940. E-mail: etkeller@umich.edu

Received 9 October 2000; Accepted 25 January 2001 
[3], intravenously (i.v.) with/without inferior vena cava occlusion $[4,5]$ or intraosseously [6,7] have been developed.

The LNCaP cell-derived series of human prostate cancer cell lines described by Thalmann et al. [3] closely mimic clinical prostate cancer progression. Specifically, the tumors secrete prostate-specific antigen (PSA), progress from androgen dependence to androgen independence and develop osteoblastic skeletal metastases. One of the cell lines, C4-2B, was isolated from metastatic prostate cancer cell lesions found in the lumbar spine of an athymic murine host. When injected orthotopically, C4-2B cells produce osteoblastic metastases in the lumbar spine. Thus, C42B cells provide a model to explore the mechanisms through which osteoblastic lesions are created.

Koeneman et al. [1] proposed that bone is a highly restricted and protective environment that prohibits the growth and survival of cancer cells and that in order to thrive in the bone microenvironment, cancer cells must acquire "osteoblastlike" properties. In agreement with this postulation, we hypothesized that $\mathrm{C} 4-2 \mathrm{~B}$ cells gain an osteoblast phenotype. Accordingly, the aim of this study was to evaluate if the osteotropic C4-2B cells gained characteristics of osteoblasts compared to their parental LNCaP cell line.

\section{MATERIALS AND METHODS}

\section{Cell Culture}

The human prostate cancer cell lines LNCaP (American Type Tissue Collection, Manassas, VA) were grown in RPMI-1640 media with $10 \%$ fetal bovine serum (FBS) and antibiotics (penicillin 1,000 U/ml, streptomycin $10 \mathrm{mg} / \mathrm{ml}$ ) (Gibco, Grand Island, NY). C4-2B cells (Urocor) were grown in T-medium $(80 \%$ Dulbecco's modified Eagle's medium (Gibco), 20\% F12K (Irving Scientific, Santa Ana, CA), 3 g/liter $\mathrm{NaHCO}_{3}, 100 \mathrm{u} /$ liter penicillin $\mathrm{G}, 100 \mu \mathrm{g} / \mathrm{ml}$ streptomycin, $5 \mu \mathrm{g} / \mathrm{ml}$ insulin, $13.6 \mathrm{pg} / \mathrm{ml}$ triiodothyronine, $5 \mu \mathrm{g} / \mathrm{ml}$ transferrin, $0.25 \mu \mathrm{g} / \mathrm{ml}$ biotin, $25 \mathrm{~g} / \mathrm{ml}$ adenine), supplemented with 5\% FBS [8]. Primary osteoblastic cells were derived from human cancellous bone explants (9). Bone specimens were collected from human subjects undergoing hip replacement. Trabecular bone chips were washed extensively in phosphate buffered saline (PBS) to remove bone marrow, and then treated by sequential digestion with Collagenase P (Boehringer Mannheim, Indianapolis, IN). Collagenase-released cells were plated and cultured in a medium containing an 1:1 mixture of Dulbecco's Modified Eagle's medium and Ham's formula 12 medium (DMEM-F12) (Gibco) supplemented with $20 \%$ FBS and antibiotics. The medium was changed twice per week. These cells expressed the phenotype of mature osteoblastic cells. MC 3T3-E1 cells were grown in the same media in which primary osteoblasts were grown. To induce mineral production, cells were supplemented with $10 \mathrm{mM} \beta$-glycerophosphate (Sigma Chemical Co., St. Louis, MO) and $50 \mu \mathrm{g} / \mathrm{ml}$ L-ascorbic acid (Sigma) for the indicated time.

\section{Detection of Mineral}

Calcium content in culture $\left(5 \times 10^{4}\right.$ cells/well of 6-well plate) was measured using standard biochemistry (Calcium assay kit 587-A; Sigma). To stain mineral, cultures were fixed in $95 \%$ ethanol at $37^{\circ} \mathrm{C}$ for 5 min, rehydrated, then stained using von Kossa's method as previously described [10]. For the alizarin red assay, the medium was removed and the cells were air dried, fixed in 50\% ethanol three times, then stained with alizarin red (Sigma; $100 \mathrm{mg} / \mathrm{ml}$ in $0.01 \%$ $\mathrm{NaOH})$ for $5 \mathrm{~min}$. After a PBS wash, retained dye was extracted in a solution of $20 \%$ methanol and $10 \%$ acetic acid, then measured at A450.

\section{Raman Microscopy}

The prostate cancer cell cultures were grown on quartz cover slips (Esco Products). Once harvested, the cover slips were placed on a quartz slide and subjected to Raman spectroscopy as previously described [11]. In the current application, the excitation source was either a Ti-sapphire CW laser (Spectra Physics) pumped by a Nd-YVO 4 laser (Spectra Physics) and tuned to $785.0 \mathrm{~nm}$ or a $785.0 \mathrm{~nm}$ diode laser (SDL). A $20 \times / 0.75$ NA Fluar objective (Zeiss) was used to focus the laser excitation to a point on the cell cultures. The backscattered Raman scatter was focused into an axial transmissive spectrograph (Kaiser Optical Systems, Inc. HoloSpec f/1.8i, 25- $\mu \mathrm{m}$ slit) and dispersed onto either a liquid-nitrogen cooled, front-illuminated charge-coupled device (CCD) camera (Photometrics) or a liquid-nitrogen cooled, back-thinned CCD camera (Princeton Instruments). The point microspectroscopy prostate cancer cell culture data were analyzed using GRAMS32 software (Galactic Industries Corporation) and MatLab software (MathWorks, Inc.). The spectra were corrected only for outliers. Once Raman-shifted, the spectra were baselined using a quadratic fit.

\section{Electron Microscopy}

Cell monolayers were fixed in $2.5 \%$ glutaraldehyde in $0.1 \mathrm{M}$ Sorensen's buffer, $\mathrm{pH}$ 7.4. They were postfixed in osmium tetroxide (1\%) in buffer followed by dehydration in a graded series of ethanol then embedded in Epon. Ultrathin sections were stained with uranyl acetate and lead citrate and viewed on a Philips CM100 transmission electron microscope (TEM) at $60 \mathrm{kV}$. 


\section{Alkaline Phosphatase Staining}

Histochemical alkaline phosphatase staining was performed using the Sigma Diagnostics Phosphatase kit (Catalog No. 86, Sigma Diagnostic, Inc, St. Louis, $\mathrm{MO})$ as directed by the manufacturer. Briefly, the adhesive LNCaP, C4-2B cells and primary human osteoblasts were washed with HBSS, fixed with citrate-acetone-formaldehyde fixative solution for 30 $\mathrm{sec}$, then stained with alkaline-dye mixture at room temperature for $15 \mathrm{~min}$. The kit is using Naphthol ASMS phosphate substrate and Fast Red Violet B for the enzyme activity determination. They were then counterstained with hematoxylin solution and evaluated using light microscopy.

\section{Reverse Transcription-Polymerase Chain Reaction (RT-PCR)}

Total RNA was isolated from cells using TRIzol method as directed by the manufacturer (Life Technologies, Gaithersburg, MD). Due to the small quantities of osteoprotegerin (OPG) mRNA we used real-time PCR for evaluation of OPG mRNA levels. One microgram of total RNA was subject to real-time PCR (LightCycler, Roche Diganostics, Indianapolis, IN) using the SYBR Green I RNA amplification kit (Roche Diagnostics). PCR reactions were mixed and incubated at room temperature for $10 \mathrm{~min}$ then subjected to 45 cycles of $94^{\circ} \mathrm{C}, 5 \mathrm{sec} ; 55^{\circ} \mathrm{C}, 10 \mathrm{sec}$; $72^{\circ} \mathrm{C}, 1 \mathrm{~min}$. The OPG primers are described elsewhere [12]. An internal titration analysis on GAPDH was done and we obtained a linear amplification suggesting the integrity of the sample RNA.

The remaining mRNA targets were evaluated by standard RT-PCR and gel electrophoresis. Cbfa1 primers were as previously described [13]. Glyceraldehyde phosphate dehydrogenease (GAPDH) primers used were sense, 5'-TGAAGGTCGGTGTGA-ACGGATTTGGTC- $3^{\prime}$ and antisense, 5'-CATGTAG-GCCATGAGGTCCACCAC-3' to generate a 960-bp fragment. Bone morphongenic protein-7 (BMP-7) primers used were sense; 5'-AGCCCGGGTAGCGCGTAGAG-3' and antisense, 5'-GCGCCGGTGGATGAAGCTCGA$3^{\prime}$ to generate a $165 \mathrm{bp}$ fragment. Bone sialoprotein (BSP) primers used were sense, $5^{\prime}$-TCAGCATTTTGGGAATGGCC- $3^{\prime}$ and antisense, 5'-GAGGTTGTTGTCTTCGAGGT-3' to generate a $660 \mathrm{bp}$ fragment. Osteocalcin $(\mathrm{OCN})$ primers used were sense, $5^{\prime}$-CATGAGAGCCCTCACA- ${ }^{\prime}$ and antisense, $5^{\prime}$-CAGATCCCACAGCGAGA-3' to generate a 495 bp fragment. Receptor activator of NFKB ligand (RANKL) primers used were sense, 5'-GGTCGGGCAATTCTGAATT-3' and antisense, 5'-GGGAATTACAAAGTGCACCAG$3^{\prime}$ to generate an $810 \mathrm{bp}$ fragment. Osteonectin (OSN) primers used were sense, 5'-ATGAGGGCCTGGAT-
CTTCTT-3' and antisense, 5'-CTGCTTCTCAGTCAGAAGGT-3' to generate a 580 bp fragment. $32-$ microglobulin, sense, 5'-ATGCC-TGCCGTGTGAACCATGT-3', and antisense 5'-AGAGCTACCTGTGGAGCAACCT $-3^{\prime}$ to generate a $300 \mathrm{bp}$ fragment. Target gene products were subjected to 38 cycles (except BMP-7 and 32 -microglobulin which were amplified 29 cycles) using AmpliTaq Gold (Applied Biosystems, California) and cycling parameters of $95^{\circ} \mathrm{C}, 6 \mathrm{~min}$, then cycling at $94^{\circ} \mathrm{C}, 15 \mathrm{sec} ; 55^{\circ} \mathrm{C}, 30 \mathrm{sec} ; 72^{\circ} \mathrm{C}, 1 \mathrm{~min}$ and $72^{\circ} \mathrm{C}, 3 \mathrm{~min}$ for the final extension.

\section{Nuclear Lysate Preparation and Western Blot Analysis}

Nuclear protein extract from cells was prepared as described previously (Lin et al., paper submitted). Briefly, cells were harvested after being washed twice in PBS buffer. For nuclei preparation, cells were resuspended in hypotonic buffer (10 $\mathrm{mM}$ HEPES$\mathrm{KOH}$ pH 7.9, $1.5 \mathrm{mM} \mathrm{MgCl} 2,10 \mathrm{mM} \mathrm{KCl}, 0.1 \%$ NP40) and incubated on ice for $10 \mathrm{~min}$. Nuclei were precipitated with $3000 \mathrm{~g}$ centrifugation at $4^{\circ} \mathrm{C}$ for $10 \mathrm{~min}$. After washing once with hypotonic buffer, the nuclei were lysed in the lysis buffer $(50 \mathrm{mM}$ Tris$\mathrm{HCl} \mathrm{pH} \mathrm{8.0,} 150 \mathrm{mM} \mathrm{NaCl}, 1 \%$ Triton X-100) and incubated on ice for $30 \mathrm{~min}$. The nuclear lysates were pre-cleared by $20,000 \mathrm{~g}$ centrifugation at $4^{\circ} \mathrm{C}$ for $15 \mathrm{~min}$. Protein concentration was measured by Bradford assays. Western blot analysis was performed as previously described (Lin and Keller, paper submitted) with rabbit anti-Cbfa1 (AML3) (Oncogene Research Product, Cambridge, MA) and visualized with chemiluminescence.

\section{Transfection and DNA Decoy}

DNA oligo sequences were designed based on the previously reported $\mathrm{Cbfa} 1$ response element sequence [14]. Wild-type Cbfa1 decoy DNA oligos were: sense, 5'-TCGAGGATATTTGCGGTTAGCA-3' and antisense, 5'-TCGATGCTAACCGCAAATATCC-3' ${ }^{\prime}$. Mutant Cbfa1 decoy DNA oligos were: sense, 5'-TCGAGGATATTGCCAATTAGCA-3 ${ }^{\prime}$ and antisense, $5^{\prime}$-TCGATGCTAATTGGCAATATCC- $3^{\prime}$. The individual oligos were annealed to their respective complementary oligos and then used to transfect cells as previously described [15] using a lipid-based transfection reagent (FuGENE6; Roche Diagnostics).

\section{RESULTS}

\section{Calcium Content of Prostate Cancer Cell Line Grown in Promineralization Media}

The primary function of osteoblasts is to form bone. Thus, to determine if prostate cancer cells have the 
capacity to form bone, we cultured nonosteotropic $\mathrm{LNCaP}$ cells and their osteotropic derivative C4-2B cells in promineralization media. Promineralization media contained (a) ascorbic acid, which allows for production of skeletal-type extracellular matrix from osteoblasts and (b) a phosphate source for hydroxyapatite formation. Nonosteoblastic cells do not produce mineral in this media (data not shown). After incubation in promineralizing media, mineralized calcium content in the cultures was measured. Due to the variation with the data we can only detect a trend $(P$ value $=0.0861)$. Data for $\mathrm{LNCaP}$ at the other time point was lower than that of 20-day old culture (date not shown). In contrast to LNCaP cells, which produced a mild increase in absolute levels of calcium, the C4-2B cells produced approximately an eight-fold increase of mineralized calcium (Fig. 1). These levels were five-fold greater than that induced by $\mathrm{LNCaP}$ cells and comparable to those that osteoblasts MC 3T3E1 produce in these conditions (Fig. 1). These data suggest that $\mathrm{C} 4-2 \mathrm{~B}$ cells gain the ability to sequester mineral compared to LNCaP cells.

\section{Alizarin Red Retention of Prostate Cancer Cell Line Grew in Promineralization Media}

To quantify the mineralized calcium retention in the culture, we performed alizarin red staining. Strong alizarin red staining was identified in $\mathrm{C} 4-2 \mathrm{~B}$ cultures (Fig. 2A) whereas LNCaP cultures were negative to staining. The alizarin red was extracted and quanti-

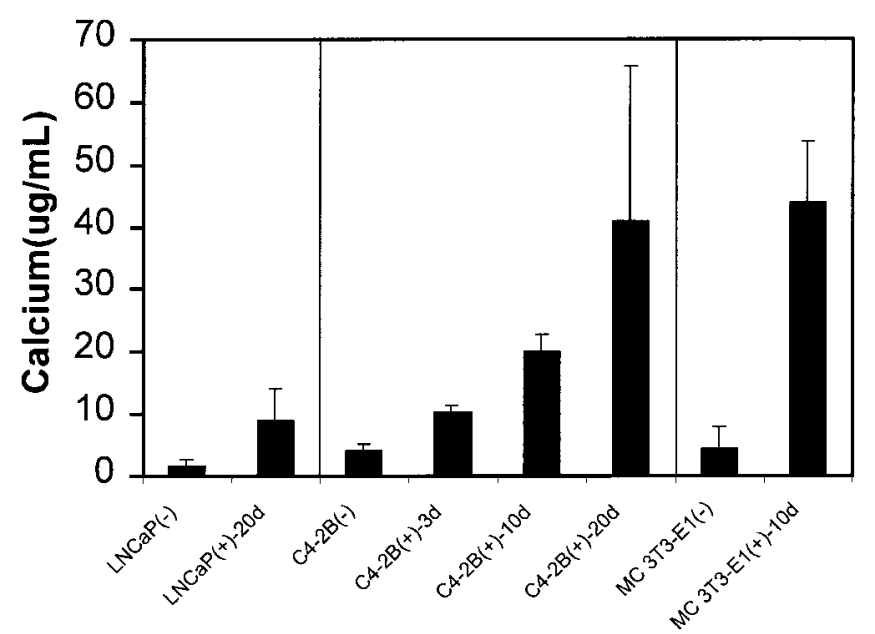

Fig. I. The calcium content increase was greater in C4-2B than $\mathrm{LNCaP}$ cells when incubated in promineralization media. Cells (C4-2B, LNCaP and MC 3T3-EI) were treated with (+) or without $(-)$ ascorbic acid $(50 \mu \mathrm{g} / \mathrm{ml})$ and $\beta$-glycerolphosphate $(10 \mathrm{mM})$ for 3 (3d), 10 (10d) or 20 (20d) days. Cells were then homogenized and calcium content were measured by calcium assay (Sigma Chemical Co.). Data obtained from three independent experiments. fied, demonstrating that $\mathrm{C} 4-2 \mathrm{~B}$ cells had increased levels, albeit lower than that of the osteoblasts MC 3T3-E1 levels, of alizarin red retention at 3 and 5 days compared to LNCaP cells (Fig. 2B).

\section{Von Kossa Staining of Prostate Cancer Cell Line Grew in Promineralization Media}

Osteoblasts form mineral deposits that contain calcium and phosphate in a nodular pattern in vitro. To determine if the calcium retention in the cells was associated with phosphate, we performed von Kossa staining. $\mathrm{C} 4-2 \mathrm{~B}$ cultures as young as 3-days-old were von Kossa positive (Fig. 3A). At 20 days, von Kossapositive nodules were present (Fig. 3B) resemble to that of the osteoblasts MC 3T3-E1 (Fig. 3D). In contrast, LNCaP cultures at 3 days were negative for von Kossa staining (not shown). Furthermore, von Kossa staining was barely detectable in $\mathrm{LNCaP}$ cultures at 20 days (Fig. 3C). These data demonstrate that C4-2B cells

A)

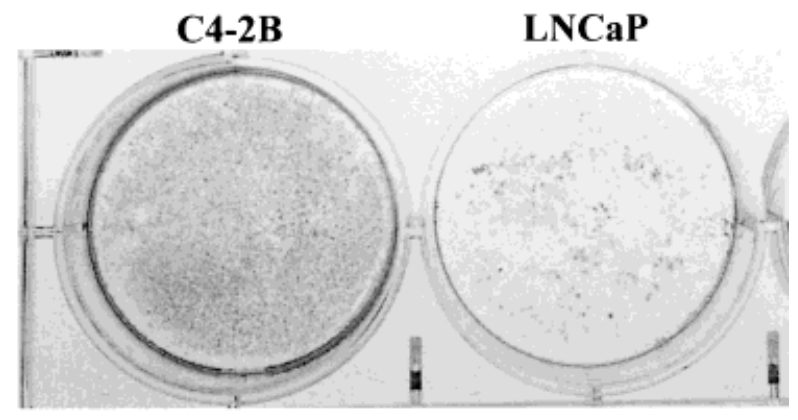

B)

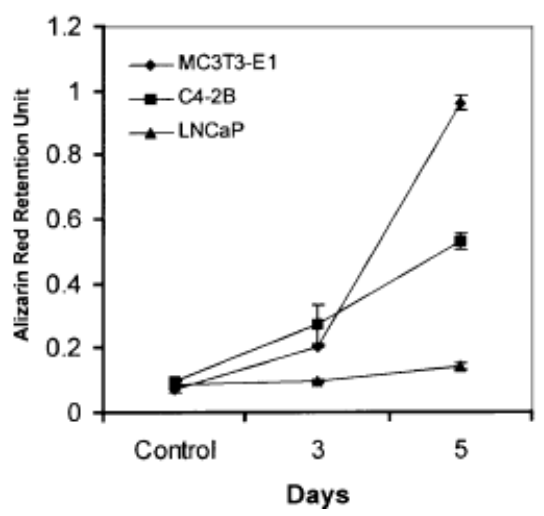

Fig. 2. $C 4-2 B$ cells had the highest increase in calcium content compared to LNCaP and MC3T3 cells over time. Cells (C4-2B, LNCaP and MC 3T3-EI) were treated with ascorbic acid $(50 \mu \mathrm{g} /$ $\mathrm{ml})$ and $\beta$-glycerophosphate $(10 \mathrm{mM})$ for 3 or 5 days. Calcium was detected using Alizarin red assay. (A) Alizarinred staining of the cells of 5-day-old culture. (B) The intensity of the mineral staining; MC 3T3-El (- - ), C4-2B (- - -), and LNCaP (- - -). Data obtained from three independent experiments. 
have gained the ability to form mineralized nodules in vitro.

\section{C4-2B Cells Cultured in Promineralization Media Produced Hydroxyapatitic Mineral}

Both Raman and infrared (IR) spectroscopies were employed in the study of mineralized tissues [16]. Raman and IR spectroscopies are complementary techniques that probe the vibrational modes of the various ions found in the specimen. Although IR spectroscopy is more familiar, Raman spectroscopy offers better spatial and spectral resolution and can be more easily performed on highly scattering specimens such as cell cultures or bone tissue itself. Although two techniques probe different vibrations of a molecule or ion, overall they provide very similar chemical information. In the Raman spectrum of mineralized tissue, the most prominent band is the phosphate v1 symmetric $\mathrm{P}-\mathrm{O}$ stretch. This band arises from the phosphate found in the hydroxyapatitic lattice that is also substituted with various other ions and the band is found in the $950-964 \mathrm{~cm}^{-1}$ region. The variability in the peak position results from the presence of a range of ionic substituents in the apatitic lattice and also reflects the crystallinity of the apatitic lattice. In bone tissue spectra, other bands due to carbonate, monohydrogen phosphate, collagen, and other matrix proteins can be present as well.

The Raman spectrum of the C4-2B cell culture at day 0 contained only weak bands characteristic of the cells and the media in which they were grown (Fig. 4A). However, the Raman spectrum of the 5-dayold culture contained a prominent band at $958 \mathrm{~cm}^{-1}$, indicative of an apatitic mineral (Fig. 4B). For comparison, we show a Raman spectrum of 1-day postnatal murine calvarial tissue (Fig. 4C). The intense apatitic phosphate $\mathrm{P}-\mathrm{O}$ stretch at $958 \mathrm{~cm}^{-1}$ is marked. Other bands characteristic of phosphate, carbonate, and normal bone matrix are visible in the spectrum. These data confirm that the C4-2B cells produce an apatitic mineral.

To examine the detailed structure of the mineral formation in individual cells, we employed TEM after 8 days of culture of the C4-2B cells in the promineralization media. Mineral deposits were often seen associated with cell membranes (Fig. 4D) as contrast to outer matrix of the osteoblasts MC 3T3-E1 (Fig. 4E).
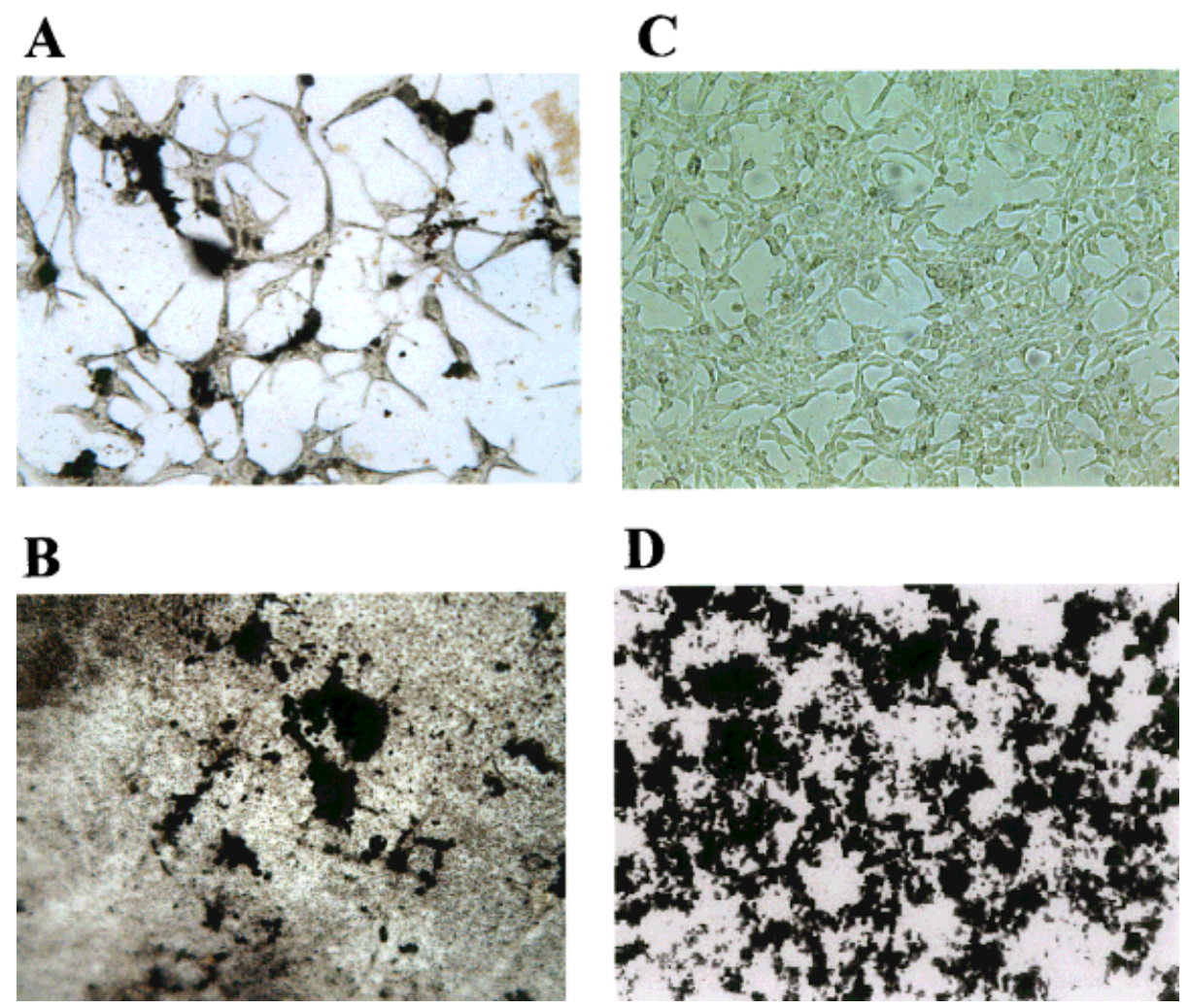

Fig. 3. $C 4-2 B$, but not $L N C a P$ cells mineralized in vitro. The cells were treated with ascorbic acid $(50 \mu \mathrm{g} / \mathrm{ml})$ and $\beta$-glycerophosphate $(10$ $\mathrm{mM}$ ) for (A) C4-2B, 3 days, $400 \times$ magnification; (B) C4-2B, 20 days, $100 \times$ magnification; (C) LNCaP, 20 days, $250 \times$ magnification; (D) MC 3T3-El, 20 days, $100 \times$ magnification; and were then fixed. Samples were then subjected to von Kossa staining to detect phosphate association (indicated by arrows). LNCaP cells showed no staining under the same incubation. 


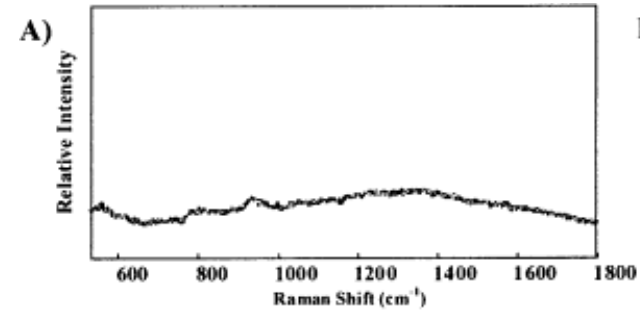

D)
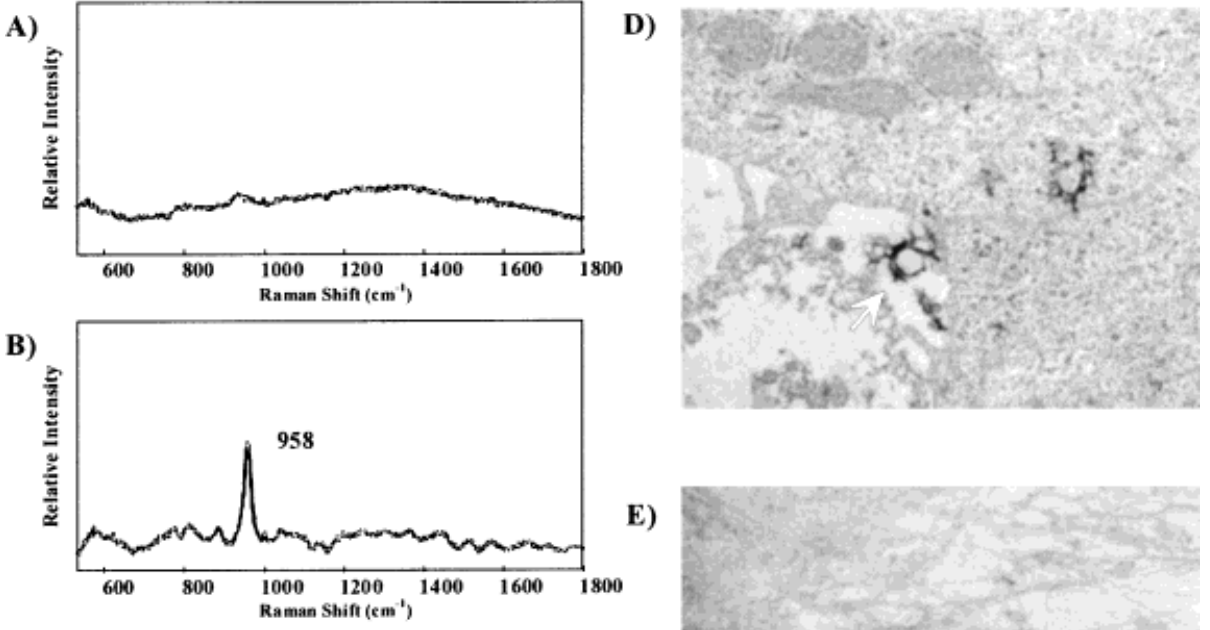

E)
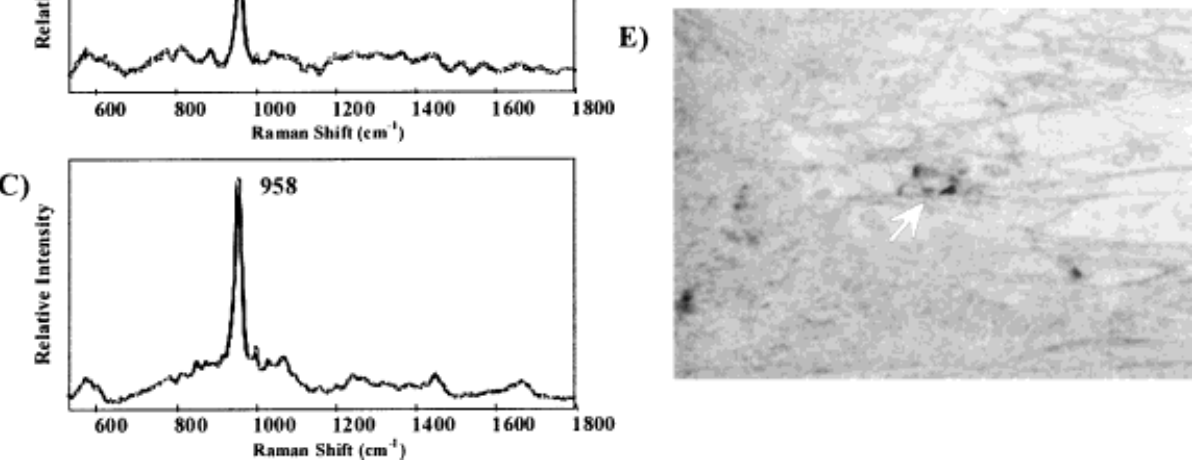

Fig. 4. C4-2B cells produced hydroxyapatitic mineral in vitro. Raman spectroscopy assay of cells in promineralization media for (A) control, (B) 5 -day-old culture, (C) a Raman spectrum of I day postnatal murine calvarial tissue; with the detection of apatitic mineral (peak 958). (D) C4-2B and (E) MC 3T3-El cells generate mineral showed by transmission electron microscopy. Cells were cultured for 8 days under the promineralization media. Cells were then visualized by TEM (7,900 $\times$ of magnification). The mineral deposit site is indicated (arrow).

Taken together, these data demonstrate that the C4-2B cells produce bonelike mineral in vitro.

\section{Osteoprotegerin Expression in Prostate Cancer Cell Line}

Two very important regulators of bone remodeling, receptor activator of $\mathrm{NF \kappa B}$ ligand (RANKL) and osteoprotegerin (OPG), have been recently identified [17]. RANKL induces osteoclastogenesis. OPG, which is expressed in a variety of tissues including osteoblasts, binds to RANKL resulting in inhibition of osteoclastogenesis $[18,19]$. Thus, it follows that overexpression of OPG by prostate cancer cells in the bone microenvironment would inhibit osteoclast activity, shifting the balance of bone remodeling in favor of bone production. This could eventually lead to osteosclerosis. Accordingly, we determined OPG mRNA expression in the $\mathrm{LNCaP}$ and $\mathrm{C} 4-2 \mathrm{~B}$ cells using realtime PCR. The OPG PCR product-increasing rate between two samples were similar (Fig. 5, LNCaPOPG vs. C4-2B-OPG). However, GAPDH level from LNCaP entered linear elevation curve approximately three cycles earlier than that of C4-2B (Fig. 5, LNCaPGAPDH vs. C4-2B-GAPDH) indicating that C4-2B expressed higher level of OPG. These data demonstrate that OPG is present in prostate cancer cells lines.

\section{Expression of Genes for Bone-Related Proteins in the Prostate Cancer Cell Line}

To further evaluate the extent of the osteoblastlike phenotype in C4-2B cells, we examined cells for the presence of alkaline phosphatase. LNCaP stained negative whereas both $\mathrm{C} 4-2 \mathrm{~B}$ and primary human osteoblast stained positive (Fig. 6A, B, and C, respectively). In addition, we evaluated $C 4-2 B$ for the expression of mRNA from a variety of genes typically expressed in osteoblasts. BSP, OCN, RANKL, and OSN mRNA were expressed in basal conditions (Fig. 6D). When the C4-2B cells were grown in promineralization media, BSP, OCN, RANKL, but not OCN mRNA levels increased. These results demonstrate that C4-2B cells share characteristics of an osteoblast.

\section{Cbfal Mediates C4-2B-Induced Mineralization}

One potential mechanism of upregulating osteoblast-related proteins in prostate cancer cells is through transcriptional activation of their gene promoters. It has been shown that Cbfa1, a transcription factor strongly expressed in osteoblasts and mildly in thymus but not other tissues $[20,21]$, plays a key role in bone development and maturation [1]. Thus, we 


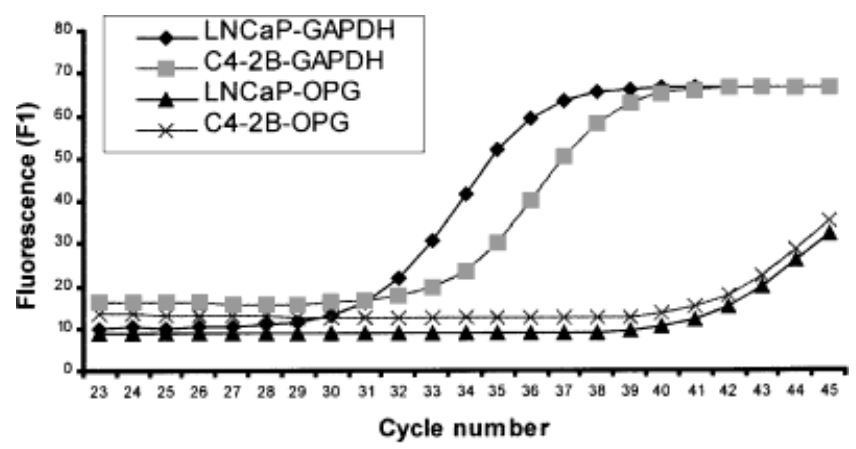

Fig. 5. C4-2B expresses higher levels of OPG mRNA than $\mathrm{LNCaP}$ cells. LightCycler fluorescence detection of GAPDH of LNCaP (- -), C4-2B (- - -) or OPG of LNCaP (- $\mathbf{\Delta}-)$, C4-2B (-x-) mRNA by PCR of total RNA from $\mathrm{C} 4-2 \mathrm{~B}$ or $\mathrm{LNCaP}$ cells.

determined Cbfa1 expression in $\mathrm{LNCaP}$ and $\mathrm{C} 4-2 \mathrm{~B}$ cells while employing human osteoblasts as positive control. Cbfa1 mRNA and nuclear protein levels were greater in C4-2B than LNCaP cells (Fig. 7A). Based on this observation and the fact that Cbfa1 induces expression of osteoblast-specific proteins that lead to bone production [20,22], we next determined the effect of inhibiting Cbfa1 activity on in vitro mineralization. We employed a "DNA Decoy" strategy by introducing either wild-type or mutant Cbfa1-binding DNA elements (Fig. 7B). Three days of promineralization media culture increased the calcium content ("basal + aa $+\mathrm{GP}^{\prime}$ vs. "basal"). The mutant decoy Cbfa1-binding DNA elements did not make significant decrease of the calcium quantity ("Dec-mt $+\mathrm{AA}+\mathrm{GP}^{\prime \prime}$ vs. "basal + aa $+\mathrm{GP}^{\prime \prime}$ ); whereas, the wild-type decoy Cbfa1-binding DNA elements decreased mineralization to base line ("Dec-wt $+\mathrm{AA}+\mathrm{GP}^{\prime}$ vs. "basal + $\left.\mathrm{aa}+\mathrm{GP}^{\prime \prime}\right)$. These data demonstrate that Cbfa1 is upregulated in C4-2B cells and that C4-2B cells induce mineralization through Cbfa1.

\section{BMP-7 is Expressed in C4-2B Cells}

It is unknown how Cbfa1 is regulated in prostate cancer cells. BMP-7 has been shown to induce Cbfa1 in

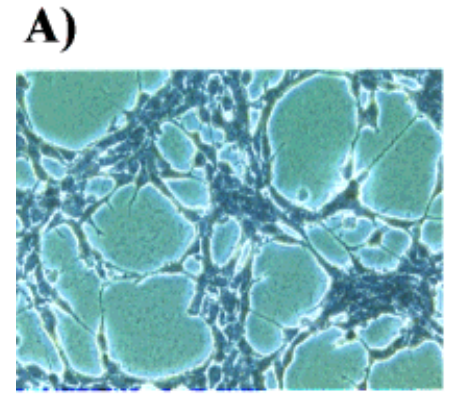

D)
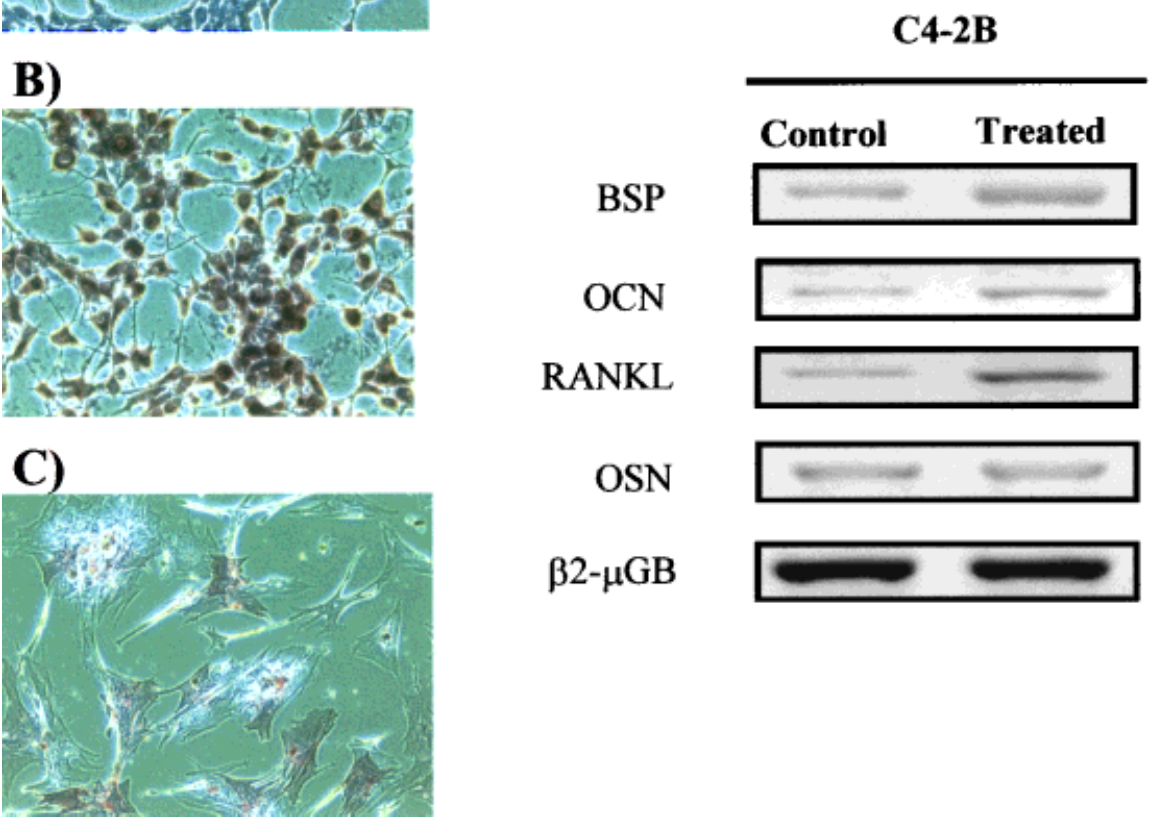

Fig. 6. C4-2B cells express bone-related proteins. (A) LNCaP, (B) C4-2B and (C) primary human osteoblast cells were examined for the activities of alkaline phosphatase (Sigma). LNCaP cells were negative, both C4-2B and primary human osteoblast stained positive (red) ( $200 \times$ of magnification). (D) Target mRNA for a variety of genes typically expressed in osteoblasts were identified by RT-PCR total RNA from $C 4-2 B$ cultured in regular or promineralization media. $\beta 2$-microglobulin $(\beta 2-\mu \mathrm{GB})$ serves as internal control. 
A)

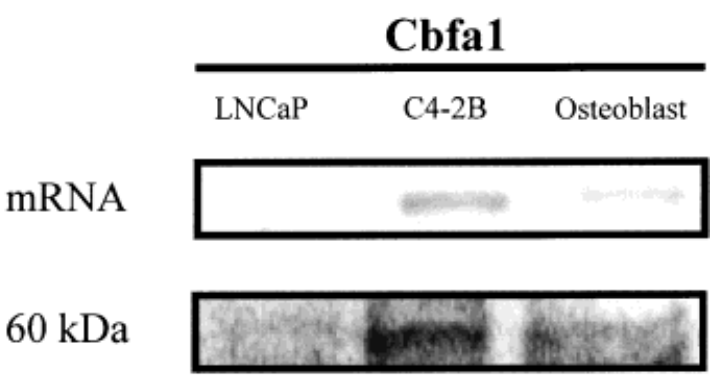

B)

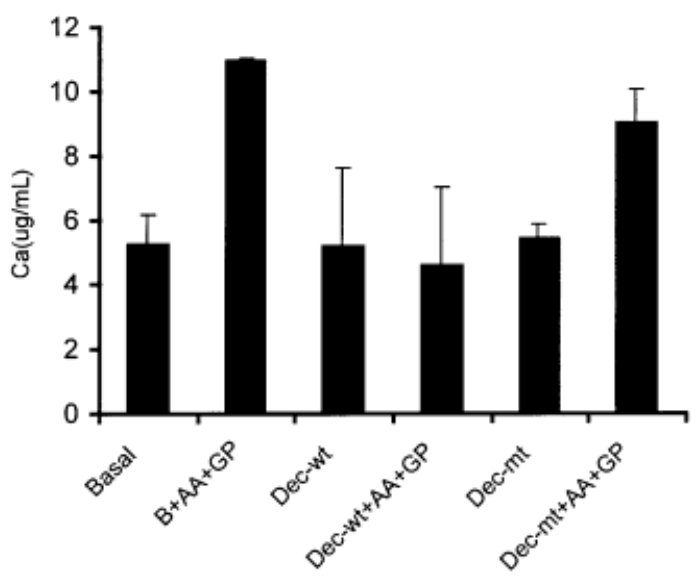

Fig. 7. $C 4-2 B$ cells express the bone-specific transcription factor, Cbfal mRNA and protein. Inhibition of Cbfal DNA binding cause reduced induction of calcium content by promineralization media. (A) Total RNA (I $\mu \mathrm{g}$ ) from LNCaP, C4 -2B, and human osteoblasts were subjected to One-step RT-PCR (Gibco-BRL) to measure Cbfal expression (upper box). Nuclear extracts $(30 \mu \mathrm{g})$ from LNCaP and C4-2B; and total lysate from human osteoblasts were subjected to anti-Cbfal (Oncogene Research Product) immunoblot to detect Cbfal (M.W. $60 \mathrm{kDa}$ ) (lower box). (B) Cells were transfected with either wild-type (Dec-wt) or mutant (Dec-mt) double-strand oligos. Cells then incubated with regular or promineralizatio media (as indicated) for 3 days and subsequently harvested and calcium content measured. Data was obtained from three independent experiments.

cells where it is not normally expressed [23]. Accordingly, we examined the expression of BMP-7 in LNCaP and C4-2B cells while employing human osteoblasts as positive control. Semiquantitative RT-PCR of total RNA from 3-days-old culture of LNCaP and C4-2B, incubated with or without promineralization medium revealed that BMP-7 expression was only detected in the $\mathrm{C} 4-2 \mathrm{~B}$ cells cultured in promineralization media (Fig. 8). Thus the data demonstrated the presence of BMP-7 in the C4-2B when stimulated by incubating the cells in the promineralization media. This finding is consistent with the ability of BMP-7 to upregulate Cbfa1.

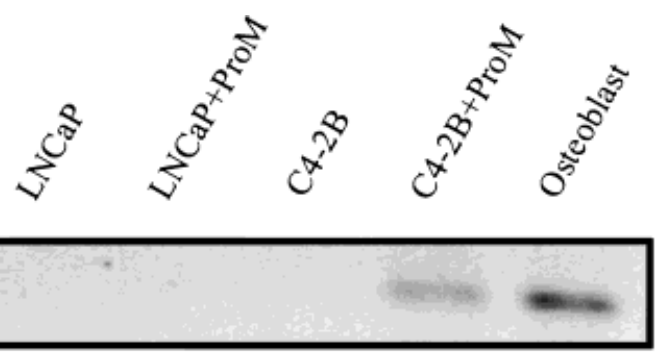

$\beta 2-\mu G B$

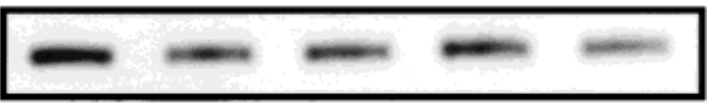

Fig. 8. $\quad C 4-2 B$ cells express $B M P-7$ when cultured in promineralization media. Total RNA (I $\mu \mathrm{g})$ from LNCaP, C4-2B and human osteoblast cells cultured 3 days in regular or promineralization (ProM) media were subjected to One-step RT-PCR (Gibco-BRL). The BMP-7 mRNAs was solely expressed in C4-2B + ProM (upper box). $\beta 2$-microglobulin was used as an internal control (lower box).

\section{DISCUSSION}

In the present study, we found that $\mathrm{C} 4-2 \mathrm{~B}$ prostate cancer cells, a cell line that metastasizes to bone, possess several aspects of an osteoblast phenotype that are not present in its parental LNCaP cell line, which does not metastasize to bone. This observation suggests that prostate cancer cells gain an osteoblastphenotype as they progress to a metastatic tumor. However, we cannot determine from the current experiments if the osteoblastlike prostate cancer cells are present prior to reaching bone or if they develop osteoblastlike properties after they reach the bone microenvironment. Regardless, our data also suggest that prostate cancer cells present in skeletal metastatic sites directly contribute to the mineral formation found in osteoblastic lesions.

The "seed-and-soil" theory proposed by Paget [24] emphasized the importance of host humoral milieu ("soil") that determines the selectivity of cancer metastasis ("seed"). Bone is a composite tissue consisting of inorganic mineral crystallite on a protein matrix. The mineral component of bone consists of calcium, phosphate, carbonate, and monohydrogen phosphate and may include a small amount of other ions [25]. Cancer cells that migrate and invade the bone must be able to adapt to this environment to survive and grow. Our data suggest that to accomplish this, the prostate cancer cells become osteoblastlike, including the ability to produce mineralized matrix.

The mechanism through which C4-2B cells produce osteoblastic lesions is not currently defined. However, our finding that OPG is increased in the C4-2B cells compared to the LNCaP cells may provide some clues to their effect on bone. OPG inhibits osteoclastogenesis 
$[18,26]$. Transgenic mice that overexpress OPG develop severe osteopetrosis owing to the arrest of terminal osteoclast differentiation [19]. Thus, in a similar fashion, the expression of OPG by C4-2B may lead to overall inhibition of osteoclast activity resulting in a shift of bone remodeling toward osteoblast activity resulting in osteosclerosis. However, our data also suggest that, in addition to the $\mathrm{C} 4-2 \mathrm{~B}$ cells stimulating osteoblasts to initiate mineralization in the bone, the C4-2B cells themselves directly initiate mineralization that occurs at the metastatic site.

Further evidence that the prostate cancer cells gained an osteoblast phenotype was provided by the observation that they expressed several osteoblastrelated noncollagenous matrix proteins including BSP, OCN, RANKL, and OSN. This observation is consistent with previous reports that osteopontin [27], OCN [28], and BSP [29] were found to be increased in LNCaP sublines and in human prostate cancer specimens. The expression of the noncollagenous matrix proteins may contribute to the ability of the C4-2B cells to mineralize. Specifically, BSP has been shown to be a crucial factor for the expression of osteoblastic phenotypes of bone marrow cells cultured [30]. When compared with nonmineralizing cells, mineralizing subclones selectively expressed mRNAs for the osteoblast markers, including BSP [31]. Furthemore, OCN and OSN are considered as the biochemical markers of bone formation [32]. Thus, the observation that the expression of these genes was increased in C4-2B cells cultured in promineralization media suggests that the bone microenvironment promotes the transition to an osteoblast-like phenotype. Since normal prostate epithelium does not express noncollagenous bone matrix proteins, these data suggest that during the malignant transformation of prostate epithelium, a switch of gene transcription toward an osteoblast phenotype must occur.

The observation that Cbfa1, a bone-specific transcription factor, was elevated in the C4-2B cells may provide the clues as to how the prostate cancer cells gain an osteoblastlike phenotype. In mice, Cbfa1 expression occurs early during skeletal development and is restricted to cells of mesenchymal condensations and cells that are associated with osteoblast lineage [20]. Targeted disruption of Cbfa1 resulted in a complete lack of bone formation and arrested osteoblast maturation [33]. Cbfa1 induces expression of several bone matrix proteins expressed by osteoblasts by binding with bone matrix protein promoters. Thus, upregulation of Cbfa1 in the cancer cells may account for the increased transcription of the osteoblast matrix proteins. This postulation is supported by our observation that inhibiting $\mathrm{Cbfa} 1$ activity diminished the ability of C4-2B cells to induce mineralization in vitro.
One mechanism that may account for upregulation of Cbfa1 is BMP-7 (also called osteogenic protein-1) expression. BMP-7, a critical mediator of bone growth [34], induces Cbfa1 expression [23]. Our observation that BMP-7 was increased in C4-2B cells is consistent with the previous report that BMP-7 is present in prostate tumors [35]. Taken together, our data suggest that BMP-7 expression in the prostate cancer cells induces Cbfa1, which in turn confers an osteoblast-like phenotype.

In summary, we have observed that the C4-2B cells gain an osteoblastlike phenotype compared to their parental LNCaP cells. It appears that upregulation of BMP-7 may induce Cbfa1, which in turn, induces expression of noncollagenous matrix proteins. The production of these proteins may account for the ability of C4-2B cells to induce mineralization, and thus produce osteosclerosis at skeletal metastatic sites.

\section{ACKNOWLEDGMENTS}

We thank Dr. Laurie K. McCauley and Dr. Renny Franceschi for valuable discussion. We also thank Ms. Dorothy Sorenson for her help with the electron microscopy. This work was supported by USAMRMC Prostate Cancer Research Program Grant \# DAMD1700-1-053, National Institutes of Health Grants SPORE 1 P50 CA69568 and R01 AG15904 and the Program in Comparative Integrative Biology and Genomics.

\section{REFERENCES}

1. Koeneman KS, Yeung F, Chung LW. Osteomimetic properties of prostate cancer cells: a hypothesis supporting the predilection of prostate cancer metastasis and growth in the bone environment. Prostate 1999;39:246-261.

2. Frank LM. Etiology, epidemiology and pathology of prostate cancer. Cancer 1997;32:1092-1095.

3. Thalmann GN, Anezinis PE, Chang SM, Zhau HE, Kim EE, Hopwood VL, Pathak S, von Eschenbach AC, Chung LW. Androgen-independent cancer progression and bone metastasis in the LNCaP model of human prostate cancer [published erratum appears in Cancer Res 1994 Jul 15;54(14):3953]. Cancer Res 1994;54:2577-2581.

4. Wang M, Stearns ME. Isolation and characterization of PC-3 human prostatic tumor sublines which preferentially metastasize to select organs in S.C.I.D. mice. Differentiation 1991;48: 115-125.

5. Shevrin DH, Gorny KI, Kukreja SC. Patterns of metastasis by the human prostate cancer cell line PC-3 in athymic nude mice. Prostate 1989;15:187-194.

6. Soos G, Zukowski K, Jones RF, Haas GP, Wang CY. Heterotopic growth of human prostate carcinoma in the femurs of nude mice: an osseous metastatic model [letter]. Int J Cancer 1996;66: 280-281.

7. Berlin O, Samid D, Donthineni-Rao R, Akeson W, Amiel D, Woods VL Jr. Development of a novel spontaneous metastasis model of human osteosarcoma transplanted orthotopically into bone of athymic mice. Cancer Res 1993;53:4890-4895. 
8. Wu TT, Sikes RA, Cui Q, Thalmann GN, Kao C, Murphy CF, Yang H, Zhau HE, Balian G, Chung LW. Establishing human prostate cancer cell xenografts in bone: induction of osteoblastic reaction by prostate-specific antigen-producing tumors in athymic and SCID/bg mice using LNCaP and lineage-derived metastatic sublines. Int J Cancer 1998;77:887-894.

9. Siggelkow H, Rebenstorff K, Kurre W, Niedhart C, Engel I, Schulz H, Atkinson MJ, Hufner M. Development of the osteoblast phenotype in primary human osteoblasts in culture: comparison with rat calvarial cells in osteoblast differentiation. J Cell Biochem 1999;75:22-35.

10. Bellows CG, Ciaccia A, Heersche JN. Osteoprogenitor cells in cell populations derived from mouse and rat calvaria differ in their response to corticosterone, cortisol, and cortisone. Bone 1998;23:119-125.

11. Timlin JA, Carden A, Morris MD, Bonadio JF, Hoffler ICE, Kozloff KM, Goldstein SA. Saptial distribution of phosphate species in mature and newly generated mammalian bone by hyperspectral raman imiging. J Biomed Opt 1999;4:28-34.

12. Huang L, Xu J, Wood DJ, Zheng MH. Gene expression of osteoprotegerin ligand, osteoprotegerin, and receptor activator of NF-kappaB in giant cell tumor of bone: possible involvement in tumor cell-induced osteoclast-like cell formation. Am J Pathol 2000;156:761-767.

13. Sasaki-Iwaoka H, Maruyama K, Endoh H, Komori T, Kato S, Kawashima H. A trans-acting enhancer modulates estrogenmediated transcription of reporter genes in osteoblasts. J Bone Miner Res 1999;14:248-255.

14. Banerjee C, McCabe LR, Choi JY, Hiebert SW, Stein JL, Stein GS, Lian JB. Runt homology domain proteins in osteoblast differentiation: AML3/CBFA1 is a major component of a bonespecific complex. J Cell Biochem 1997;66:1-8.

15. Kuratsukuri K, Sugimura $K$, Harimoto $K$, Kawashima $H$, Kishimoto T. "Decoy" of androgen-responsive element induces apoptosis in LNCaP cells. Prostate 1999;41:121-126.

16. Carden A, Morris MD. Application of vibrational spectroscopy to the study of mineralized tissues (review) [In Process Citation]. J Biomed Opt 2000;5:259-268.

17. Hofbauer LC, Khosla S, Dunstan CR, Lacey DL, Boyle WJ, Riggs BL. The roles of osteoprotegerin and osteoprotegerin ligand in the paracrine regulation of bone resorption. J Bone Miner Res 2000;15:2-12.

18. Yasuda H, Shima N, Nakagawa N, Mochizuki SI, Yano K, Fujise N, Sato Y, Goto M, Yamaguchi K, Kuriyama M, Kanno T, Murakami A, Tsuda E, Morinaga T, Higashio K. Identity of osteoclastogenesis inhibitory factor (OCIF) and osteoprotegerin (OPG): a mechanism by which OPG/OCIF inhibits osteoclastogenesis in vitro. Endocrinology 1998;139:1329-1337.

19. Simonet WS, Lacey DL, Dunstan CR, Kelley M, Chang MS, Luthy R, Nguyen HQ, Wooden S, Bennett L, Boone $T$, Shimamoto G, DeRose M, Elliott R, Colombero A, Tan HL, Trail G, Sullivan J, Davy E, Bucay N, Renshaw-Gegg L, Hughes TM, Hill D, Pattison W, Campbell P, Boyle WJ. Osteoprotegerin: a novel secreted protein involved in the regulation of bone density [see comments]. Cell 1997;89:309-319.

20. Ducy P, Zhang R, Geoffroy V, Ridall AL, Karsenty G. Osf2/ Cbfa1: a transcriptional activator of osteoblast differentiation [see comments]. Cell 1997;89:747-754.

21. Ryoo HM, Hoffmann HM, Beumer T, Frenkel B, Towler DA, Stein GS, Stein JL, van Wijnen AJ, Lian JB. Stage-specific expression of Dlx-5 during osteoblast differentiation: involvement in regulation of osteocalcin gene expression. Mol Endocrinol 1997;11:1681-1694.

22. Xiao G, Cui Y, Ducy P, Karsenty G, Franceschi RT. Ascorbic acid-dependent activation of the osteocalcin promoter in MC3T3- E1 preosteoblasts: requirement for collagen matrix synthesis and the presence of an intact OSE2 sequence. Mol Endocrinol 1997;11:1103-1113.

23. Tsuji K, Ito $Y$, Noda M. Expression of the PEBP2alphaA/ AML3/CBFA1 gene is regulated by BMP4/7 heterodimer and its overexpression suppresses type I collagen and osteocalcin gene expression in osteoblastic and nonosteoblastic mesenchymal cells. Bone 1998;22:87-92.

24. Paget $\mathrm{S}$. The distribution of secondary growths in cancer of the breast. Lancet 1889;1:571-573.

25. Kaplan FS, Hayes WC, Keaveny TM, Boskey A, Einhorn TA, Iannotti JP. In Orthopaedic basic science. Rosemont: American Acedemy of Orthpaedic Surgeons; 1994. p. 127-184.

26. Tsuda E, Goto M, Mochizuki S, Yano K, Kobayashi F, Morinaga $\mathrm{T}$, Higashio K. Isolation of a novel cytokine from human fibroblasts that specifically inhibits osteoclastogenesis. Biochem Biophys Res Commun 1997;234:137-142.

27. Thalmann GN, Anezinis PE, Chung LW, Devoll R, RFarachCarson C. Experimental approaches to skeletal metastasis of human prostate cancer. Principles Pract Genitourin Oncol 1997;409-416.

28. Gardener TA, Ko SC, Kao C, Shirakawa T, Cheon J, Gotoh A, Wu TT, Sikes RA, Zhau HE, Cui O, Balian G, Chung LWK. Exploiting stromal-epithelial interaction for model development and new strategies of gene therapy for prostate cancer and osteosarcoma metastases. Gene Ther Mol Biol 1998;41-58.

29. Waltregny D, Bellahcene A, Van Riet I, Fisher LW, Young M, Fernandez P, Dewe W, de Leval J, Castronovo V. Prognostic value of bone sialoprotein expression in clinically localized human prostate cancer. J Natl Cancer Inst 1998;90:1000-1008.

30. Mizuno M, Imai T, Fujisawa R, Tani H, Kuboki Y. Bone sialoprotein (BSP) is a crucial factor for the expression of osteoblastic phenotypes of bone marrow cells cultured on type I collagen matrix. Calcif Tissue Int 2000;66:388-396.

31. Wang D, Christensen K, Chawla K, Xiao G, Krebsbach PH, Franceschi RT. Isolation and characterization of MC3T3-E1 preosteoblast subclones with distinct in vitro and in vivo differentiation/mineralization potential. J Bone Miner Res 1999; 14:893-903

32. Gundberg CM. Biochemical markers of bone formation [In Process Citation]. Clin Lab Med 2000;20:489-501.

33. Komori T, Yagi H, Nomura S, Yamaguchi A, Sasaki K, Deguchi K, Shimizu Y, Bronson RT, Gao YH, Inada M, Sato M, Okamoto R, Kitamura Y, Yoshiki S, Kishimoto T. Targeted disruption of $\mathrm{Cbfa1}$ results in a complete lack of bone formation owing to maturational arrest of osteoblasts [see comments]. Cell 1997;89: 755-764.

34. Reddi AH. Bone morphogenetic proteins: an unconventional approach to isolation of first mammalian morphogens. Cytokine Growth Factor Rev 1997;8:11-20.

35. Weber KL, Bolander ME, Rock MG, Pritchard D, Sarkar G. Evidence for the upregulation of osteogenic protein-1 mRNA expression in musculoskeletal neoplasms. J Orthop Res 1998; $16: 8-14$. 